\title{
An Application for Learning Malay Language as a Second Language: A Proposed Design
}

\author{
Saipunidzam Mahamad, a , Haslinda Mohamaddiah, ${ }^{1, b}$, \\ Mohammad Noor Ibrahim ${ }^{1, ~ c}$, Faizal Ahmad Fadzil ${ }^{1, d}$, Rozana Kasbon ${ }^{1, e}$ \\ ${ }^{1}$ Department of Computer and Information Sciences, Universiti Teknologi PETRONAS \\ Bandar Seri Iskandar, 31750 Tronoh, Perak MALAYSIA \\ asaipunidzam_mahamad@petronas.com.my, blindalala90@gmail.com, \\ cmnoor_ibrahim@petronas.com.my, ${ }^{d}$ faizal_ahmadfadzil@petronas.com.my, \\ 'rozank@petronas.com.my
}

Keywords: Malay language, mobile application, early child education

\begin{abstract}
With the proliferation of wireless and mobile technologies, this paper presents a framework for learning Malay language as a second language for vernacular primary school students through a mobile application. One of the problems faced by this group of students is when they have to further their studies to national secondary school where the medium of communication is no longer in their native language, but Malay.. This application encourages the learners to improve their Malay language skills at their own pace anytime anywhere. It is designed in such a way that the learners can use and explore the modules in the application by themselves. The concept of play and learn is integrated in this application that gives excitement in learning the language.
\end{abstract}

\section{Introduction}

Language is very important for a nation. Malay language is the national language for Malaysia. As Malaysia is a multi races, cultures and religions, national language plays an important role to unite the entire citizen. Lately, we have seen that the language is losing its originality not only in daily conversations but also in writing. Therefore, preservation of the language is one of the Malaysian government's awareness programs targeting the young generation.

Generally, a Malaysian is able to speak in at least two languages which are Malay and English. For a group of people who is not using Malay language as their mother tongue, they are able to speak in three different languages including their native language. In learning a language, memorizing and practicing are two important aspects in order for us to understand a vocabulary and its usage in the right context. In Malaysia, there are at least two types of primary schools; national and vernacular primary school programs. In vernacular schools, Malay language is taught as a second or third language after Chinese, English or Tamil.

Least number of vernacular secondary schools in Malaysia has driven a massive number of students from vernacular primary schools to proceed their studies in national secondary schools. It is a good approach to encourage students to master the national language. Students should have a strong foundation of the language in order to survive in national secondary schools. Sometimes, teachers are having a lot of difficulties in teaching and communicate with students as this group of students is unable to understand the Malay language. This surely will distract the teaching and learning process.

This paper proposes an interactive design of mobile application that could help learners to learn Malay language as a second language. This design integrates the current syllabus that emphasizes on daily usage of the language such as recognizing alphabets, numbers and objects. With the provided modules, learners will be able to measure their ability in mastering the language. The mobility and ability to support multimedia content is the factor of the booming in android mobile phone. Therefore, our intention in introducing mobile application as an alternative learning tool is to create an excitement among the learners that promising more fun learning. 


\section{Related Work}

Language is a cognitive system of symbols for the expression of thought and indication of decent [1]. In Malaysia, language is a unification platform for different races that lived in the main land. Malay language is synonym with Malay citizens as their mother tongue; however with diversity of races, Malay language is a universal language that can make communication possible between people [2]. Since the 15th Century, the Malay language is lingua franca during the Sufis and Muslim traders' process of introducing Islam to the native people in the region and in the creation of colonies comprising Eastern and Western trade groups [3].

The first language acquired by children is considered as their mother tongue [4]. In Malaysia, Malay language is taught in the vernacular schools. Three types of vernacular school have been introduced in Malaysia since 1786 by the British Colony which is Malay, Chinese, and Tamil. Even tough, Malay language is a national language but it is taught as second language in Chinese and Tamil schools. The awareness of introducing learning Malay language using Mobile arise to make learning Malay effective and more convenient for the minority people.

Some parents prefer to start their children school education at age of 6 before going to formal education system. According to statistic by Ministry of Education Malaysia till 30th June 2011, about $3.33 \%$ children enrolled for preschool education, compared to children enrolled for primary school and secondary school are $53.30 \%$ and $43.47 \%$ respectively. This shown that, there is a little number of children have basic education in literacy competencies at early age. Preschool education plays a vital role in shaping children learning development and rapid growth [5]. The aim of preschool education is to educate citizens with high-level skills and competency in a global society. The education system in Malaysia is organized to reflect the ethnic diversity in consideration of the various ethnic groups [6].

When discussing about children development, it is usually about physical, mental, social and emotional development. In learning language, mental and social development plays an important role to develop their ability to memorize and practice. Although children are not been taught second language since toddler, the ability of learning second language at early age is possible and would be a great advantage for a child. During the first three years of life, the foundations for thinking, language, vision, attitudes, aptitudes, and other characteristics are laid down. Consequently, it would be a waste not to use a child's natural ability to learn during his or her most vital years, when learning a second language is as easy as learning the first [7].

The more fun been introduced, the more a child will have a tendency to stay with it. Learning while playing is the best way to learn because it creates emotional attachments, and emotion is the door to learning. Interactivity via visualization and practicing in learning will help children in learning second language faster [8,9]. Children can easily memorize thing when they learn by doing, talking, playing, connect with numbers and pictures, and through pictures and sounds. Visual or multimedia content are highly motivated students to learn because they are amusing and interesting. Previously, web based application become a phenomenon when people start to adapt interactivity in learning in schools. Applying web based application for educational purpose is not a new concept. Thorough the computer technologies, computer based learning and teaching become more interactive and interesting [7].

\section{System Framework}

The methodology comprises two main stages is shown in Fig. 1. The first stage is the early analysis, which consists of problem identification and objective determination. The second stage is the application development. The main objective of this proposed system is to encourage students to learn language and memorize necessary vocabularies that will be using often in their daily lives. The approaches and lessons are based on the preschool and primary schools in Malaysia that teach Malay as their second language. Thus, the content of the lessons and games are age-appropriate. Prototype will be tested to the real users to see the result and feedback from them. 


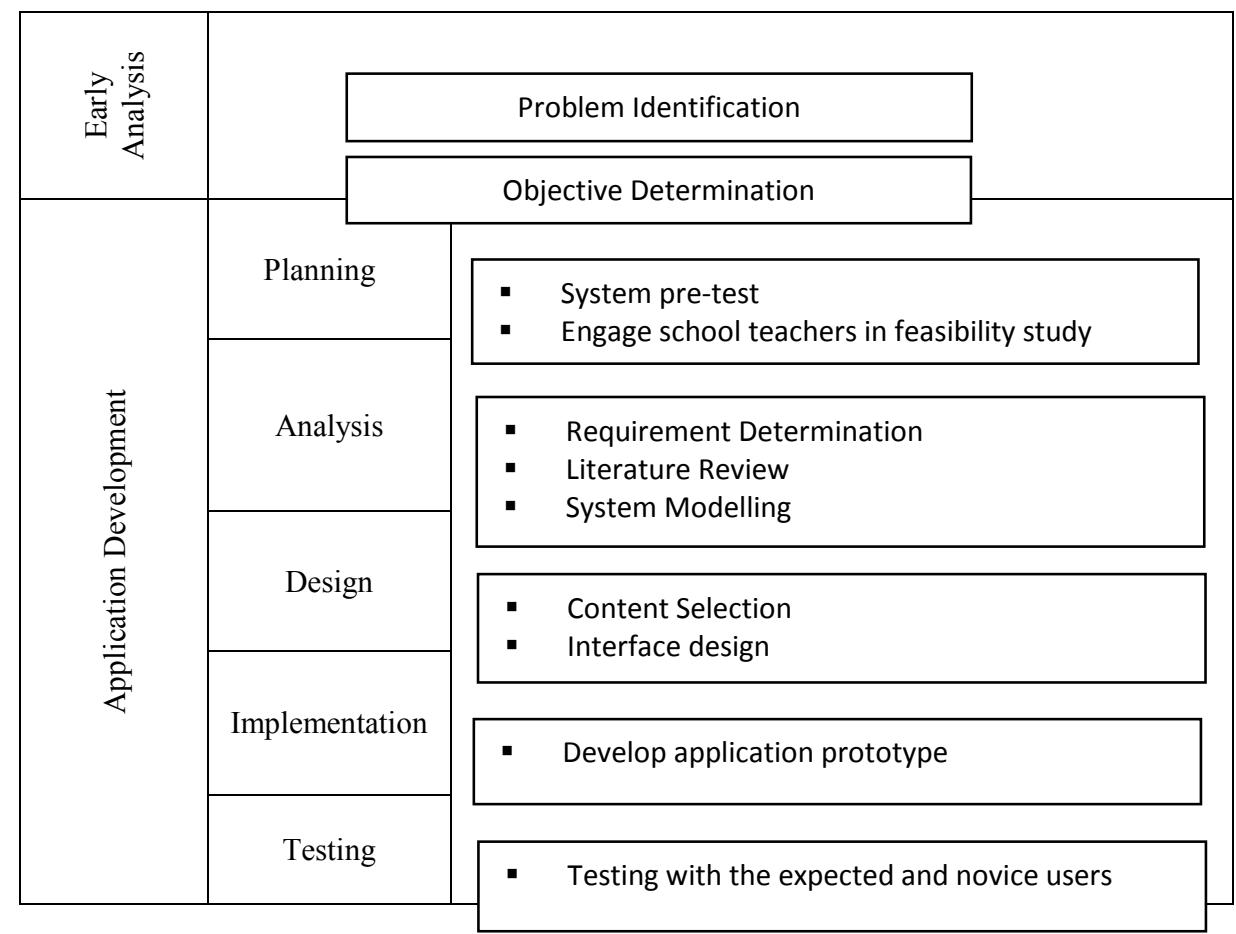

Fig. 1: Methodology

The proposed system architecture for mobile learning using mobile is shown in Fig. 2. Web server is the base for communication between server and client. Learning content contains data for the modules and will be loaded directly into the mobile phone once it gets connected to the internet. The idea of separation the learning content and user management is to ease developer for any added content in the future. This makes the application to be more scalable. The users will invoke the communication by accessing their mobile application and request will be sent over the network to be connected with the servers and learning content.

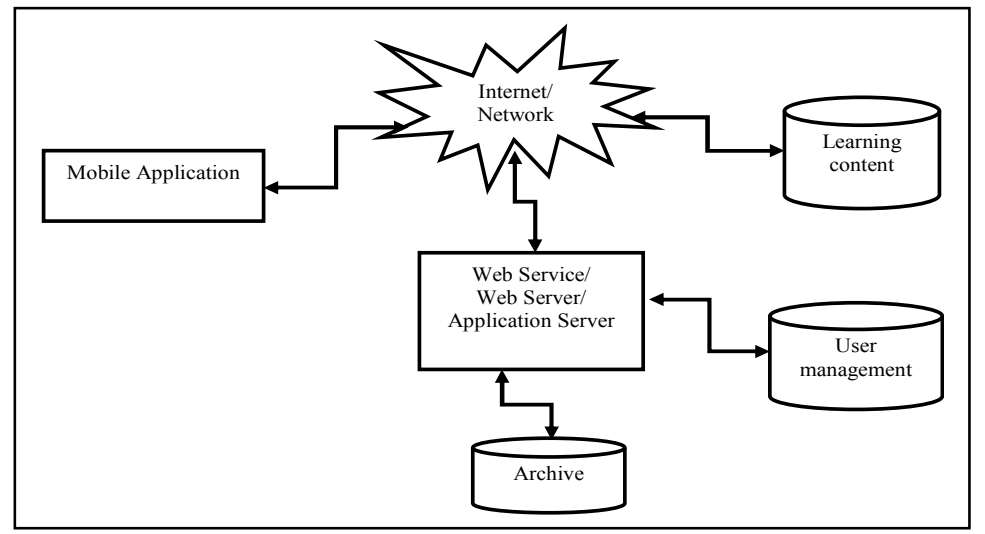

Fig. 2: The proposed system architecture

The class diagram represents in Fig. 3 is the initial database structure and its relationship of the application. There are five main tables which are Student, Tutor, Module, Progress and Answer. There section in the diagram represents the class name, attributes for the class and method that invokes the class operation. The will be three modules will be embedded in the system for learning and activities. Students will be able to develop the skills from one module to another level as the level of learning is increasing to stimulate the student's thinking behavior. The learning process happens through the module as student needs to think to play the modules. Result for each module will be stored to Archive database and be reviewed by tutor. 


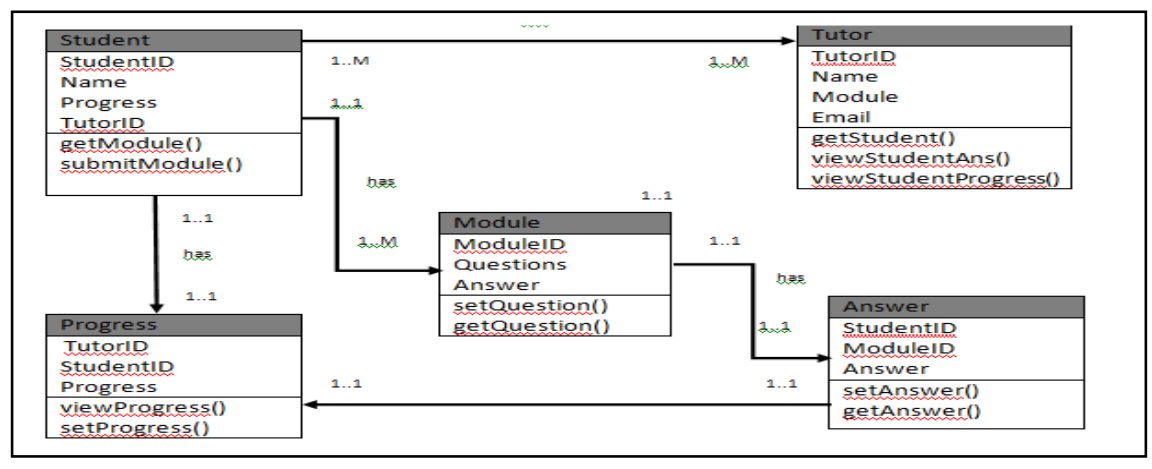

Fig. 3: Class diagram

The UML use case diagram in Fig. 4 represents the proposed interaction between each table in the database system. Each student is uniquely identified by studentID that will be set after their one-time registration before having access to the application. The student table is connected to three tables, module, tutor and progress. Once the module is completed, it will be connected to the answer as student cannot view the answers before completing the module activities. The progress table keeps each students progress and it also can be viewed by the tutor for monitoring student's progress. All the data will be kept in the database in the server and can be retrieved anytime when connected to the internet.

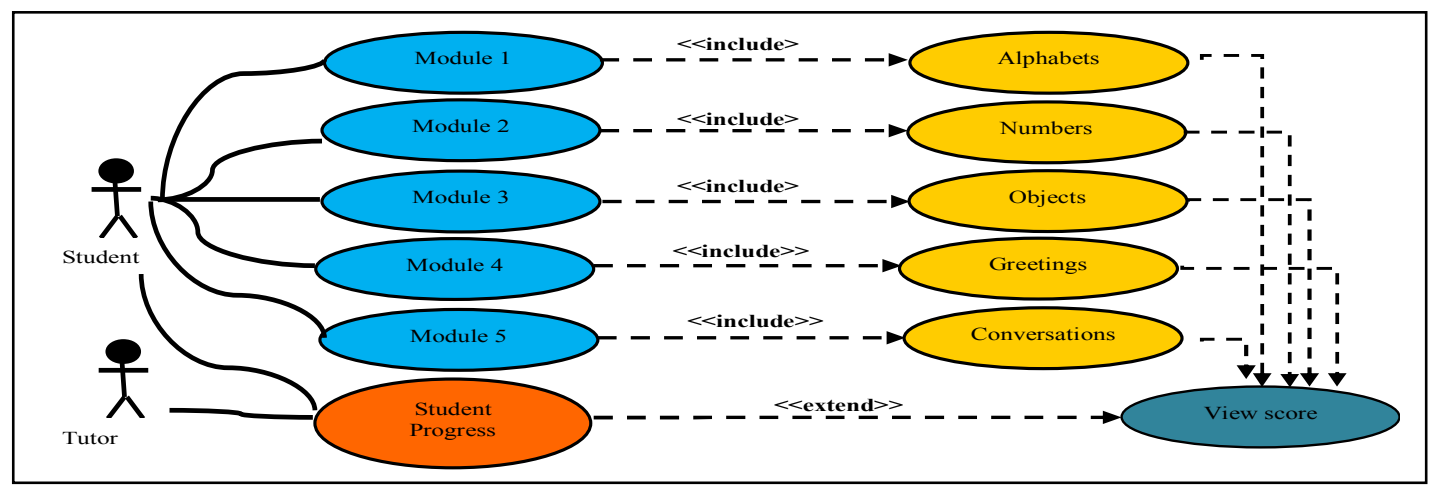

Fig. 4: Use case diagram

\section{System Design}

This application provides five main modules that can develop basic Malay language skills for children who learn Malay language as their second language. Learning language involves a lot of memorization and practice to make the children understand more about the concept and usage of words. Each module is designed based on the capabilities of the student in the early age to support the children development process. In the early development of the application, the modules chosen includes "alphabets", "numbers", "objects", "greeting" and common "conversation" that can be used in daily life. The module chosen is high in level from one module to another module to stimulate the development process of learning language. The module chosen is based on the school children level and the fundamental knowledge for learning language instead of having vocabulary, adverbs, conjunctions and others because it requires a lot of process and quite complicated.

The development will be constructed using games approach to make children feel more attractive, motivated and enjoying while learning thus, tend to learn more. The designated game only involved simple games as fill in the blank, matching the words, arranging alphabets and others. It is because the main goal of this application is to support learning Malay language education among student in the early age and promote enjoyment of learning using Android application. Via interactive mobile learning, children can learn by themselves without having active one-to-one learning process in the class or tuition. Other than that, the usage of graphics and bright colors play an important role to make the application more interesting. 
Three options that user might select in home screen which is choose lesson, view answer, and tutor. The first choice will navigate user to the choose lesson screen whereby it contains list of module; in this application it involves five main modules. Users can select which module that they want to try; lesson 1 is the easiest module, lesson 3 is an intermediate module and lesson 5 is the advance module. Answers are provided once the users complete the module by choosing the second option in the home screen. To view the overall progress by users, tutor can choose the third option and see the performance of each user. The overall process is shown in the figure 1, 2 and 3 provided.

\section{Conclusion}

Learning a language with the aid of ICT is not a new approach in the educational system but it is getting popular nowadays as the technology advances. With this application, learning session can be done not only within class hours, but anytime anywhere. Learning process is more fun and attractive by using mobile application as current mobile devices support multimedia elements. The integrated concept of learning while playing can be beneficial for the learner where they will indirectly get some inputs while playing. In future, this application will have more exercises, so that learners will not only mastering Malay language, but they are able to speak and practice their pronunciations. Now, learners do not have limitation in their learning. Hope, this application will help them understand the lessons easily and apply those in their daily lives. As a result, this application will increase the awareness of using standard Malay language among citizen of Malaysia.

\section{Reference}

[1] Tham S.C. A Study of The Evolution of The Malay Language Social Change and Cognitive Development. Singapore: Singapore University Press Kent Ridge. 1990

[2] Viacheslav A. C. The problem of the Caucasian Sprachbund. From Lingustic Areas to Areal Linguistics 31. 2008

[3] Mehmet O. A Brief Overview of Relations Between Malay Language and National Awareness. Universiti Teknologi Malaysia, Malaysia. 2011

[4] Aishah Md kassim. Malay Language As A Foreign Language And The Singapore's Education System.Journal of Language Studies, 8(1),47-56. (2008)

[5] Barnett W. S. Preschool Education and its lasting Effect:Research and Policy implication.National Institue for Early Education Research, The state University of New Jersey. 2008

[6] Akiko K. Early Childhood Education In Malaysia: A Comparison with Japan.Waseda University (2007).

[7] Lamb A. And Johnson Larry. "Flash: engaging learners through animation, interaction and multimedia". Teacher Librarian 33 Vol.4, page 54-56, (2006).

[8] Mahamad S., Kaoemanee Y., Ibrahim M. N. and Kasbon R.. A Flash-Based Framework for Learning Thai Language as Second Language in Preschool Education. Software Engineering and Knowledge Engineering: Theory and Practice Advances in Intelligent and Soft Computing Volume 115, 2012, pp 115-122

[9] Kotani T. et al. “An Analysis on the Process from Play to Learning”, IEEE, page 231 -234. (2004) 